\title{
IS DICLOFENAC GARGLE EFFECTIVE IN ALLEVIATING POST-TONSILLECTOMY PAIN IN ADULTS?
}

\author{
Acharya $A^{1^{*}}$, Singh $\mathrm{MM}^{2}$, Pandey $B R^{3}$, Pokharel $B^{4}$, Pandit $S B^{5}$, Bartaula $S^{5}$
}

\section{Affiliation}

1. Associate Professor, Department of ENT \& Head and Neck Surgery, Universal College of Medical Sciences, Bhairahawa, Nepal

2. Associate Professor, Department of ENT \& Head and Neck Surgery, Lumbini Medical College, Palpa, Nepal

3. Assistant Professor, Department of ENT \& Head and Neck Surgery, Lumbini Medical College, Palpa, Nepal

4. Assistant Professor, College of Nursing, Lumbini Medical College, Palpa, Nepal

5. Resident, Department of ENT \& Head and Neck Surgery, Lumbini Medical College, Palpa, Nepal

\section{ARTICLE INFO}

Received : 14 May, 2020

Accepted : 28 July, 2020

Published : 05 October, 2020

(C) Authors retain copyright and grant the journal right of first publication with the work simultaneously licensed under Creative Commons Attribution License CC - BY 4.0 that allows others to share the work with an acknowledgment of the work's authorship and initial publication in this journal.

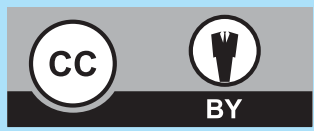

ORA 177

DOI: https://doi.org/10.3126/bjhs.v5i2.31377

\section{* Corresponding Author}

Dr. Anup Acharya

Associate Professor

Department of ENT \& Head and Neck Surgery

Universal College of Medical Sciences, Bhairahawa, Nepal Email ID: anupent@gmail.com

ORCID ID: https://orcid.org/0000-0003-1638-1103

\section{Citation}

Acharya A, Singh MM, Pandey BR, Pokharel B, Pandit SB, Bartaula S. Is Diclofenac Gargle Effective in Alleviating Post-tonsillectomy Pain in Adults? BJHS 2020;5(2)12: 1031-1034.

\section{ABSTRACT}

\section{Introduction}

Pain in the post-operative period is a major concern following tonsillectomy in an adult resulting in prolonged hospital stay, decreased oral intake and absence from work. Various techniques and medications have been tried to reduce the pain.

\section{Objectives}

We attempted to study the efficacy of diclofenac gargle in reducing the post-tonsillectomy pain in adults.

\section{Methodology}

We conducted a double-blind randomized study in patients 18 years or older undergoing tonsillectomy. Cases were given diclofenac gargle in post-operative period whereas controls were given normal saline gargle. Other modality of treatment and medication were same in both the groups. Pain was assessed at rest and during swallowing with Visual Analogue Score (VAS) on first and second post-operative day, and then at the end of first and second week of the surgery. Pain scores between two groups were compared.

\section{Results}

There were 64 participants equally divided into cases and controls by block randomization. Pain score during swallowing was significantly less in cases. The difference at rest was not significant at any point of time studied. The pain gradually increased over a week in both the groups and then rapidly decreased by the end of second week.

\section{Conclusion}

Diclofenac gargle is effective in reducing the posttonsillectomy pain, especially during swallowing, in adults.

\section{KEYWORDS}

adults, diclofenac, local anesthesia, pain management, tonsillectomy 


\section{INTRODUCTION}

Tonsillectomy is one of the most commonly performed surgery in otolaryngology. Post-operative pain management is an important aspect following tonsillectomy, especially in adults. ${ }^{1}$ The pain may be severe enough for the patients to miss work or studies for days, if not weeks. Various techniques and analgesics have been tried to reduce this pain. Local injection of anesthetic agents like lidocaine or bupivacaine, parenteral dexamethasone during induction of anesthesia, non-steroidal anti-inflammatory drugs (NSAIDs) like ketorolac or diclofenac, or opioids by various routes, local injection of ketamine, and their combinations are the most commonly used methods. ${ }^{2,3}$ Other modalities to reduce the pain include application of hyaluronic acid in the tonsillar fossa after surgery, covering up of tonsillar fossa with mucosal flaps or floseal etc. ${ }^{4.5}$ Diclofenac has been used routinely by dental doctors and is found to act as local anesthetic via various mechanism of action. ${ }^{6}$ It has been commonly used by dental doctors but is rare in otolaryngology practice. We attempted to assess the efficacy of diclofenac gargle in alleviating post-tonsillectomy pain in adults.

\section{METHODOLOGY}

It was a double-blind randomized trial conducted in Department of Otolaryngology in Lumbini Medical College Teaching Hospital. The study was done from $15^{\text {th }}$ April, 2018 to $14^{\text {th }}$ January, 2020. It was approved by the Institutional Review Committee of the Hospital.

Sample size calculation was based on a study by Ng TT et al. in which median pain score in post-tonsillectomy adult patients among placebo group was 7 (range 0 - 10). We assumed diclofenac gargle would be able to reduce this pain by at least $20 \%$. Considering standard deviation as onefourth of the mean value, alpha error to be $5 \%$ and power be $80 \%$, minimum sample size in each group would be 25 . We included 32 patients in each group. Thus, there were a total of 64 patients.

All adults (18 years and above) undergoing tonsillectomy for benign cause were included. Patients undergoing tonsillectomy along with additional procedure like adenoidectomy, uvulopharyngoplasty, tongue base reduction etc. were excluded from the study. Those who were on drugs that might affect the pain score, specially analgesics, steroids and neurotropic medications were also excluded. Patients not consenting to the study or having allergy to any of the drugs used in the study were also excluded.

The participants were explained about the nature of the study and written informed consent was taken from each participant. The patients were randomized into two groups, cases and controls, by block randomization using blocks of four.

All tonsillectomies were done under general anesthesia
(GA) by consultant surgeons with bipolar cautery. Injection dexamethasone $8 \mathrm{mg}$ was given intravenous (IV) at the time of induction of GA and one gram of paracetamol, as infusion, at the end of the surgery to all the patients. Then, all the patients received $500 \mathrm{mg}$ of oral paracetamol every six hours. Injection ketorolac $30 \mathrm{mg}$ IV was given as required for breakthrough pain and was recorded.

Diclofenac gargle $(0.074 \% \mathrm{w} / \mathrm{v})$ was given to the cases. Gargling was done with $10 \mathrm{ml}$ of solution for 5 minutes, and then spat out, starting after six hours of surgery once they were fully awake, three times a day. Control group was made to gargle with normal saline, which was available as a $100 \mathrm{ml}$ commercial pack, with the same volume and frequency.

Pain scoring was done with the help of visual analogue score (VAS) ranging from 0 to 10 where 0 indicated no pain at all and 10 indicated most severe pain that could be imagined of. VAS has been tested as a reliable and valid too to measure pain and discomfort in various circumstances. ${ }^{7.9}$ Scoring was done before the morning round on postoperative days 1 and 2 by a trained nurse who was not involved in care of the patient and was thus blinded. Scoring was done for pain at resting and during swallowing. Participants were trained and instructed to record the both scores at one week post-surgery. They were instructed to follow-up at two weeks with histopathology report for review during which pain assessment was also done.

The data were entered in Microsoft Excel ${ }^{\mathrm{TM}} 2008$ and imported to SPSS ${ }^{\mathrm{TM}} 16$ (Statistical Package for Social Sciences) for analysis. All the paper proforma were preserved for any future reference. Descriptive statistics were presented as mean, standard deviation (SD), frequency and percentages. Categorical data were analyzed with chisquare test. Normally or near-normally distributed pain scores were compared with parametric test (T-test). Severely skewed pain scores were compared with nonparametric test (Mann-Whitney $U$ test). $P$ value less than 0.05 was considered as statistically significant.

\section{RESULTS}

There were altogether 64 participants divided equally into two groups. There were $25(39 \%)$ males and the rest were females. Mean age of the participants was 29.77 years $(\mathrm{SD}=7.91)$.

Scores for pain at rest and during swallowing for both group at post-operative day 1 and day 2, and at one week were near normally distributed. Pain score for both group at two weeks post operation was severely right skewed, so they were compared with non-parametric test. The details of their comparison are shown in Table 1 which shows that the resting pain in both groups were comparable at all assessment time-period from surgery whereas pain scores at swallowing were statistically significantly lower in cases at all time-period. 
Table 1: Comparison of pain score at rest and during swallowing at various period in cases and control group.

\begin{tabular}{|c|c|c|c|c|c|}
\hline Period & $\begin{array}{l}\text { Events: } \\
\text { Pain at - }\end{array}$ & $\begin{array}{c}\text { Case } \\
\text { Mean (SD) }\end{array}$ & $\begin{array}{c}\text { Control } \\
\text { Mean (SD) }\end{array}$ & Statistics & Remarks \\
\hline \multirow[t]{2}{*}{ Day 1} & rest & $2.53(1.27)$ & $2.97(1.03)$ & $t=1.51, p=0.14$ & \multirow{2}{*}{$\begin{array}{l}\text { Independent } \\
\text { t-test }\end{array}$} \\
\hline & swallowing & $5.34(1.26)$ & $6.31(1.09)$ & $t=3.29, p=0.002^{*}$ & \\
\hline \multirow[t]{2}{*}{ Day 2} & rest & $3.72(1.42)$ & $3.81(1.18)$ & $t=0.29, p=0.78$ & \multirow{2}{*}{$\begin{array}{l}\text { Independent } \\
\text { t-test }\end{array}$} \\
\hline & swallowing & $6.06(1.56)$ & $6.94(1.22)$ & $t=2.5, p=0.02^{*}$ & \\
\hline \multirow[t]{2}{*}{1 week } & rest & $3.31(0.69)$ & $3.72(0.92)$ & $t=1.9, p=0.051$ & \multirow{2}{*}{$\begin{array}{l}\text { Independent } \\
t \text {-test }\end{array}$} \\
\hline & swallowing & $6.16(0.85)$ & $7.03(.93)$ & $t=3.93, p<0.001^{*}$ & \\
\hline \multirow{2}{*}{2 weeks } & rest & $\begin{array}{c}\text { mean rank }= \\
31.12\end{array}$ & $\begin{array}{c}\text { mean rank } \\
=33.88\end{array}$ & $U=468, p=0.4$ & $\begin{array}{l}\text { Mann-Whitney U } \\
\text { test }\end{array}$ \\
\hline & swallowing & $\begin{array}{c}\text { mean rank }= \\
21.27\end{array}$ & $\begin{array}{c}\text { mean rank } \\
=43.73\end{array}$ & $\mathrm{U}=152, \mathrm{p}<0.001^{*}$ & $\begin{array}{l}\text { Mann-Whitney U } \\
\text { test }\end{array}$ \\
\hline
\end{tabular}

* statistically significant

The trend of the pain score over time in both groups is shown in Figure 1 which shows that the pain score in control group is higher throughout and it gradually increases from first post-operative day for a week and then sharply declines by the end of second week

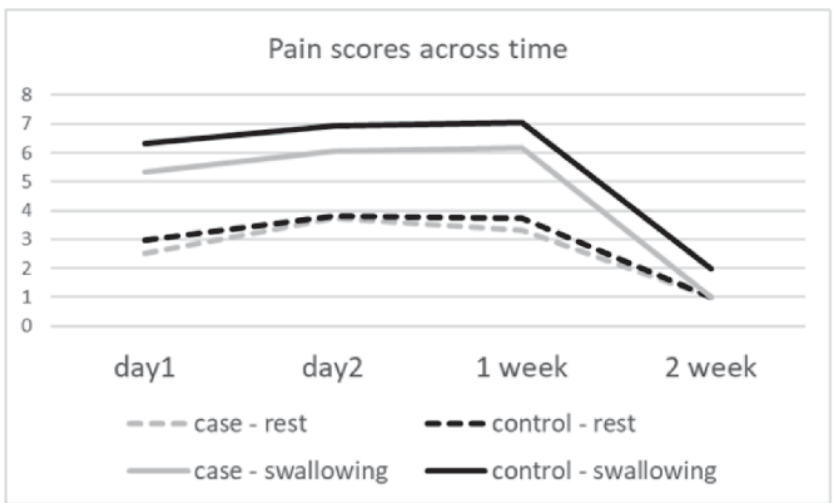

Figure 1: Pain scores over time in both groups

Breakthrough pain with the need of additional analgesia was observed in 8 (25\%) participants among control group and $3(9.4 \%)$ among cases. This difference was not statistically significant $\left(X^{2}=2.74, \mathrm{df}=1, \mathrm{p}=0.098\right)$.

\section{DISCUSSION}

The objective of this study was to compare role of diclofenac gargle in alleviating post-tonsillectomy pain in adults and we found that it was successful specially in reducing the pain during swallowing.

Pain is a common complain following tonsillectomy. Up to $13.1 \%$ of patients may complain of pain despite routine postoperative analgesia. ${ }^{10}$ Adults may miss their work and children remain absent from school for several days following tonsil surgery due to throat pain and poor oral intake as a result of this pain. The causes of this significant pain are attributed to sensitivity of tonsillar fossae to tissue damage, the pharyngeal muscle spasms specially during swallowing, the disruption of mucosa, and vagal and/or glossopharyngeal nerve fiber irritation. ${ }^{4}$ Our experience was that the patients were comfortable to some extent following surgery but had pain during swallowing.

Various techniques have been tried to reduce posttonsillectomy pain. Electrocautery, laser, harmonic scalpel, and coblation have not been able to produce consistent results. Powered intracapsular tonsillectomy, though not as popular as other methods, has shown promising results in decreasing postoperative pain. ${ }^{11,12}$ Analgesics including paracetamol, Nonsteroidal anti-inflammatory drugs (NSAIDs) including diclofenac, opioids, cryosurgery, steroids, fibrin glue, nerve blocks, gabapentin or pregabalin, and topical sucralfate has been tried. Paracetamol, NSAIDs, and opioids are routinely used in post-operative period. Other modalities need further studies to clarify their effectiveness. ${ }^{11,13}$

Majority of our participants were females. Tonsils related disease is more common in females and is found to exceed the ratio by $2: 1{ }^{14}$ This explains larger number of female participants in the study. We found that the resting pain scores at all time-period following surgery were comparable in two groups whereas pain during swallowing was significantly less in cases at all time-period. This implies that the topical diclofenac was successful in alleviating posttonsillectomy pain during swallowing but not at rest. Though mechanism of action of diclofenac is known as inhibition of prostaglandin synthesis by inhibiting cyclooxygenase-1 (COX-1) and cyclooxygenase-2 (COX-2) enzymes almost equally, there are updates with other mechanisms. ${ }^{6}$ These mechanisms include inhibition of thromboxane-prostanoid receptors, alter arachidonic acid release and uptake, suppress action of lipoxygenase enzymes, and activation of nitric oxide-cGMP antinociceptive pathway. Additionally, diclofenac may inhibit substrate $P$, block acid-sensing ion channels and alter interleukin- 6 production. These may be the reasons why it was effective as a topical anesthesia. ${ }^{6}$

We found that the post-tonsillectomy pain perceived by the participants in both groups gradually increased over a week, and then rapidly decreased by the end of second. Natural course of pain following tonsillectomy was studied by kim et al. and found that the pain gradually decreases over a week and then decreases rapidly. Pain was greater in adults above 18 years of age. Mean VAS score for pain on day 1 was 6.4 which decreased to 5.3 in a week and then decreased to 1.6 at the end of two weeks. This finding was different from our study in that the pain decreased gradually over first week despite the fact that the same technique was applied as ours. They had used bipolar cautery for dissection and hemostasis. However, in another study by Ozkiris et al., the pain with the cautery method increased gradually over a week and then decreased rapidly at the end of second week. ${ }^{12}$ This study supports the finding of our study that pain increased gradually over a week and then decreased rapidly over next week.

Frequency of use of pain medication for breakthrough pain was higher in the control group as compared to that of cases. However, this difference was not statistically significant. $P$ value $(p=0.09)$ was not very far from the point of significance. Further studies with increase in sample size or consideration of other factors might change the value.

Various variables have been found to determine degree of pain following tonsil surgery. A study found female gender, age $<20$ years, absence of pain counselling, pre-existing 
chronic pain, and receiving opioids in post-operative period were associated with higher postoperative pain score. ${ }^{15} \mathrm{We}$ did not attempt to study the determinants of severity of pain as it was not our objective. Post-tonsillectomy pain might depend on the technique of surgery. It is found to be higher when surgery is done with cautery as compared to classic cold steel dissection. In a study by Ozkiris et al., mean pain score with cautery method was significantly higher than that compared to steel dissection. ${ }^{12}$ However, another study which compared pain with monopolar cautery method with cold steel dissection and coblation dissection did not find any significant difference. ${ }^{16}$ We carried out tonsil surgery in all participants with bipolar cautery.

\section{CONCLUSION}

Pain is a major morbidity in post-tonsillectomy period, particularly during swallowing and in the first week after surgery. Diclofenac gargle was successful in reducing this pain throughout the period of two weeks after surgery, especially for the pain related to swallowing. We recommend diclofenac gargle in tonsillectomy patients who can gargle as a routine for pain management.

\section{RECOMMENDATION}

We recommend the use of diclofenac gargle in postoperative period following tonsillectomy in adults to reduce surgery related pain. Further studies those consider multi-factorial analysis for factors that may affect posttonsillectomy pain would be of greater value to support the use of topical diclofenac.

\section{LIMITATIONS OF THE STUDY}

There could have been various factors that would have affected the severity of pain in the post-operative period for eg, duration of surgery, handling of tissue of tonsil bed, extend of application of cautery etc. We did not consider those factors in our study which might have produced some different outcome.

\section{CONFLICT OF INTEREST}

None

\section{FINANCIAL DISCLOSURE}

No financial aid was available for the study

\section{REFERENCES}

1. Kim M-S, Choi HG, Park E-K, Kim SY, Kim J-H, Park B. Natural course of tonsillectomy pain: A prospective patient cohort study. Auris Nasus Larynx. 2018 Jun 1;45(3):508-13. DOI: 10.1016/j.anl.2017.07.018

2. Hansen J, Shah RD, Benzon HA. Management of pediatric tonsillectomy pain: a review of the literature. Ambul Anesth. 2016;20(6):23-6. DOI: 10.2147/AA.S98896

3. Erhan ÖL, Göksu H, Alpay C, Beştaş A. Ketamine in posttonsillectomy pain. Int J Pediatr Otorhinolaryngol. 2007 May 1;71(5):735-9. DOI: 10.1016/j.ijporl.2007.01.008

4. Hancı D, Altun H. Effectiveness of hyaluronic acid in posttonsillectomy pain relief and wound healing: A prospective, doubleblind, controlled clinical study. Int J Pediatr Otorhinolaryngol. 2015 Sep 1;79(9):1388-92. DOI: 10.1016/j.ijporl.2015.07.016

5. Mozet C, Prettin C, Dietze M, Fickweiler U, Dietz A. Use of Floseal and effects on wound healing and pain in adults undergoing tonsillectomy: randomised comparison versus electrocautery. Eur Arch Otorhinolaryngol. 2012 Oct 1;269(10):2247-54. DOI: 10.1007/s00405-011-1904-4

6. Gan TJ. Diclofenac: an update on its mechanism of action and safety profile. Curr Med Res Opin. 2010 Jul 1;26(7):1715-31. DOI: 10.1185/03007995.2010.486301

7. Haefeli M, Elfering A. Pain assessment. Eur Spine J. 2006 Jan;15 (Suppl 1):S17-24. DOI: 10.1007/s00586-005-1044-x

8. Carlsson AM. Assessment of chronic pain. I. Aspects of the reliability and validity of the visual analogue scale. Pain. 1983 May $1 ; 16(1)$ : 87-101. DOI: 10.1016/0304-3959(83)90088-X

9. Bijur PE, Silver W, Gallagher EJ. Reliability of the Visual Analog Scale for Measurement of Acute Pain. Acad Emerg Med. 2001;8(12): 1153-7. DOI: 10.1111/j.1553-2712.2001.tb01132.x
10. Seshamani M, Vogtmann E, Gatwood J, Gibson TB, Scanlon D. Prevalence of Complications from Adult Tonsillectomy and Impact on Health Care Expenditures. Otolaryngol Neck Surg. 2014 Apr 1;150(4):574-81. DOI: 10.1177/0194599813519972

11. Kim D-H, Jang $\mathrm{K}$, Lee $\mathrm{S}$, Lee HJ. Update review of pain control methods of tonsil surgery. Auris Nasus Larynx. 2020 Feb 1;47(1):42-7. DOI: 10.1016/j.anl.2019.10.002

12. Özkiriş M, Kapusuz Z, Saydam L. Comparison of three techniques in adult tonsillectomy. Eur Arch Otorhinolaryngol. 2013 Mar 1;270(3):1143-7. DOI: 10.1007/s00405-012-2160-y

13. El-Hakim H, Nunez DA, Saleh HA, MacLeod DM, Gardiner Q. A randomised controlled trial of the effect of regional nerve blocks on immediate post-tonsillectomy pain in adult patients. Clin Otolaryngol Allied Sci. 2000;25(5):413-7. DOI: 10.1046/j.13652273.2000.00397.x

14. Abouzied A, Massoud E. Sex differences in tonsillitis. Dalhous Med J [Internet]. 2008 Sep 12 [cited 2020 May 12];35(1). DOI: $10.15273 / \mathrm{dmj}$.Vol35No1.3919

15. Guntinas-Lichius O, Geißler K, Komann M, Schlattmann P, Meissner W. Inter-Hospital Variability of Postoperative Pain after Tonsillectomy: Prospective Registry-Based Multicentre Cohort Study. PLoS ONE [Internet]. 2016 Apr 27 [cited 2020 May 11];11(4). DOI: 10.1371/journal.pone.0154155

16. Álvarez Palacios I, González-Orús Álvarez-Morujo R, Alonso Martínez C, Ayala Mejías A, Arenas Brítez O. Postoperative Pain in Adult Tonsillectomy: Is There Any Difference Between the Technique? Indian J Otolaryngol Head Neck Surg. 2017 Jun 1;69(2):187-93. DOI: 10.1007/s12070-017-1058-9 